\section{Rifampin plus Metronidazole for Clostridium difficile Infection}

To the Editor-In their thorough joint Society for Healthcare Epidemiology of America-Infectious Diseases Society of America clinical practice guidelines for Clostridium difficile infection (CDI), Cohen et al $^{1}$ address a large body of literature on an extremely important disease. For the most part, I found myself in agreement with the majority of their recommendations and their assessment of the quality of the evidence on which they were based. However, in the subsection titled "Treatment of a first episode of CDI," the authors understated the risks of adding rifampin to metronidazole. They state that "a recent trial did not show any trend toward better results when rifampin was added to a metronidazole regimen." (p 447) In fact, the referenced trial showed that combination therapy with rifampin and metronidazole resulted in significantly higher mortality, compared with that of treatment with only metronidazole ( $32 \%$ vs $5 \% ; P=.04){ }^{2}$

Because $C$. difficile infection and relapse has become more frequent, ${ }^{3}$ we may find that clinicians will be trying new therapies, especially if they are unaware of associated harms. Thus, it is important that when a randomized clinical trial reveals evidence of harm, it is not trivialized. Although this finding comes from a single trial, it is compatible with other data suggesting that the addition of rifampin to other antimicrobials is not benign. ${ }^{4}$ Characterizing the addition of rifampin to metronidazole for CDI only as lacking in efficacy, while ignoring the observed serious harms, increases the chance that this combination will be used by well-meaning clinicians. The addition of rifampin to metronidazole for CDI should be viewed as probably harmful and thus avoided.

\section{ACKNOWLEDGMENTS}

Potential conflicts of interest. D.M.D. reports no conflicts of interest relevant to this article.

Dimitri M. Drekonja, MD, MS

From the Infectious Diseases Section, Minneapolis Veterans Affairs Medical Center, and the Department of Medicine, University of Minnesota, Minneapolis, Minnesota.

Address reprint requests to Dimitri M. Drekonja, MD, MS, Infectious Diseases (111F), Minneapolis VA Medical Center, 1 Veterans Drive, Minneapolis, MN 55417 (drek0002@umn.edu).

Infect Control Hosp Epidemiol 2010; 31(11):1205

(C) 2010 by The Society for Healthcare Epidemiology of America. All rights reserved. 0899-823X/2010/3111-0022\$15.00. DOI: $10.1086 / 657078$

\section{RE F E REN CES}

1. Cohen SH, Gerding DN, Johnson S, et al. Clinical practice guidelines for
Clostridium difficile infection in adults: 2010 update by the Society for Healthcare Epidemiology of America (SHEA) and the Infectious Diseases Society of America (IDSA). Infect Control Hosp Epidemiol 2010;31:431455.

2. Lagrotteria D, Holmes S, Smieja M, Smaill F, Lee C. Prospective, randomized inpatient study of oral metronidazole versus oral metronidazole and rifampin for treatment of primary episode of Clostridium difficileassociated diarrhea. Clin Infect Dis 2006;43:547-552.

3. Aslam S, Hamill RJ, Musher DM. Treatment of Clostridium difficile-associated disease: old therapies and new strategies. Lancet Infect Dis 2005;5: 549-557.

4. Deresinski S. Vancomycin in combination with other antibiotics for the treatment of serious methicillin-resistant Staphylococcus aureus infections. Clin Infect Dis 2009;49:1072-1079.

\section{Reply to Drekonja}

To the Editor-We thank Dr Drekonja ${ }^{1}$ for his letter, which accurately describes the study of Lagrotteria et al ${ }^{2}$ that reported increased mortality in the metronidazole plus rifampin arm of a randomized study of the treatment of Clostridium difficile infection (CDI) with metronidazole versus metronidazole plus rifampin. We note that the excess mortality in this study arm was attributed to CDI in only one of the cases as an immediate cause of death, and in their discussion the authors state, "none of the deaths could be attributed to the combination of metronidazole and rifampin." ${ }^{\text {"(p552) }}$ The other deaths appear to have been related to additional infections, congestive heart failure, respiratory failure, or pancreatic cancer, as shown in Table $3 .^{2}$ Thus, it is not at all certain that increased mortality is related to the treatment regimen for CDI. In preparing the guidelines, we discouraged use of antibiotic combinations for CDI, hence the statement: "There is no evidence to support administration of combination therapy to patients with uncomplicated CDI." ${ }^{\text {( }(\mathrm{p} 44)}$ The letter by Dr Drekonja ${ }^{1}$ only serves to reinforce this recommendation; however, it is not at all certain that there was attributable harm to patients from combination treatment with metronidazole plus rifampin. ${ }^{2}$

\section{ACKNOWLEDGMENTS}

Potential conflicts of interest. S.H.C. reports that he has been a member of the speakers' bureau for Viropharma and Wyeth and has been a consultant to Genzyme, Salix, and Romark. D.N.G. reports that he has been a consultant for ViroPharma, Optimer, Cepheid, Merck, Schering-Plough, Actelion, Astellas, Medicines Co., and TheraDoc; has received research support from ViroPharma, Optimer, Cepheid, Gojo, Merck, and Sanofi Pasteur; and holds patents for the prevention and treatment of CDI licensed to ViroPharma. S.J. reports that he has been an advisor to Astellas, Bio- $\mathrm{K}+$, Optimer, and Viropharma. 